\title{
Thomas Henderson and $\alpha$ Centauri
}

\author{
Brian Warner \\ Department of Astronomy, University of Cape Town, Rondebosch 7700, South Africa \\ email: warner@physci.uct.ac.za
}

\begin{abstract}
The first observations containing evidence of a measurable stellar parallax were made by Thomas Henderson at the Cape of Good Hope in 1832/33. Although his response to Manuel Johnson's discovery in early 1833, that $\alpha$ Cen has a large proper motion, was to intensify observations for his remaining month at the Cape, Henderson apparently saw no urgency to reduce his observations. Instead he laboured through more routine matters, producing a catalogue of declinations of southern stars, improvements of refraction tables, and work on the solar and lunar parallaxes. It was Bessel's announcement of a determination of the parallax of 61 Cyg that finally stirred Henderson into action in late 1838.
\end{abstract}

\section{Introduction}

Thomas Henderson was born in Dundee in 1798 and showed early talent. At the age of fifteen he was apprenticed to a solicitor and in his spare time began to study astronomy. In 1819 he moved to Edinburgh and completed his legal studies, meeting the local astronomers and being allowed to use the observatory on Calton Hill. From the age of 26 on Henderson published a number of papers, mostly on computational methods, and he narrowly missed being appointed to the astronomy Professorship at Edinburgh and to the Superintendency of the Nautical Almanac Office. Although technically an amateur astronomer he was elected a Fellow of the Royal Society.

When the Directorship of the Cape Observatory came available through the death of Fearon Fallows in 1831, he was persuaded to take the post, largely as a way in which to enter the professional arena of astronomy.

While becalmed in Falmouth, on his way to the Cape, he wrote to his friend and fellow amateur astronomer, Thomas Maclear, that “...I received my official instructions. They prescribe a sufficient amount of work. In the Southern hemisphere I am asked to do as much as now occupies twelve or twenty Observatories in the northern. However I am not at all daunted. Patience and perseverance can do much. I am required to pay particular attention to the Transit of Mercury; but as nothing is said with regard to those of Venus, I conclude that it is held a settled point that I shall not be alive at the first one that happens, which I believe is in 1874" (Henderson 1832).

Henderson held the position of His Majesty's Astronomer at the Cape of Good Hope for a mere 13 months, arriving at the Observatory on 8 April 1832 and leaving for England on 28 May 1833, soon to become the first Astronomer Royal for Scotland. During his time at the Cape he assiduously observed the brighter southern stars with the mural circle, resulting in a catalogue of precise declinations for 172 stars, which was dated at Edinburgh on 30 September 1836 (Henderson 1838a). As he naturally included $\alpha$ Centauri among his selected objects he serendipitously made measurements that were the first to be affected by a detectable parallax. However, the mural circle had problems, which had caused Fearon Fallows, Henderson's predecessor at the Cape, great anguish (Warner 1979, 1995) and which Henderson himself investigated with considerable care soon after 
arriving at the Capet (Henderson 1835). Sheepshanks \& Airy (1833), using observations made by Fallows, and Henderson from his own observations, all concluded that a reliable measurement could be obtained if a mean was taken of the six microscopes attached to the mural circle. Henderson's successor, Thomas Maclear, together with John Herschel, also investigated the circle and eventually arranged for it to be exchanged with its twin, which was in use at Greenwich and arrived at the Cape in July 1839. (On investigation in London the steel collar on one of the pivots of the Cape mural circle was found to be loose: Warner 1979)

It is natural to expect that Henderson would be cautious about any claim to what would be the first true detection of stellar parallax, particularly when Brinkley had had his fingers burnt on the subject some fifteen years earlier (Brinkley 1815; Pond 1817). But the delay, which was of over four years, was a surprising length of time, considering the apparent importance of the matter and that Henderson had already told Maclear in June 1834 that "It is certain that $\alpha^{1}$ and $\alpha^{2}$ Centauri have an annual proper motion of $33^{\prime \prime} 6$ in space...They should be watched to see if parallax be visible in them" (Henderson $1834 \mathrm{~b})$.

Henderson's paper on the parallax of $\alpha$ Cen was dated in Edinburgh 24 December 1838; it was read at the RAS meeting on 3 Jan 1839 and appears in Volume 11 of Mem RAS, dated 1840 on the title page (when the volume was completed). In his paper Henderson states "It was only about the termination of my residence at the Cape, that I learned from Mr Johnson the fact of the great proper motion, which first made me suspect that there might be a sensible parallax. Had I been aware of the proper motion at an earlier period, a much greater number of observations, and as such as would have been better adapted for ascertaining the parallax, would have been made, so that a greater degree of probability would have attended the result".

\section{Manuel Johnson}

Manuel John Johnson had been appointed in 1823 to the South Atlantic island of St Helena as part of the St Helena Artillery, which was detailed to protect the tomb of Napoleon Bonaparte. On St Helena Johnson was taught land surveying and showed such proficiency that he was selected to erect an observatory to provide accurate time for the ships at Jamestown. To increase his knowledge of meridian astronomy he was permitted to visit the Royal Observatory at the Cape of Good Hope, where Fearon Fallows was in the process of erecting the Observatory. Johnson visited Fallows in early 1826 and again in late 1828. From Fallows he was able to copy the plans of the central section of the Cape observatory, which he adapted for the observatory on Ladder Hill in St Helena. On his second visit he was able to practice with the meridian instruments that had just been installed at the Cape.

By April 1833 Johnson had been at St Helena for 10 years and was entitled to furlough with pay. His application stated that he intended to "visit the principal European

$\dagger$ Consider what Maclear, on his way to the Cape in 1833, must have felt when he received Henderson's warning about the mural circle, which was one of the two principal instruments that Maclear was expected to employ in making the most accurate possible measurements of star positions: "Be not alarmed although you find sudden and violent changes in the readings of the top and bottom Microscopes of the Circle when directed to the same Star on two successive nights, for what one gains, its opposite will lose, and the mean of both and of all the six will remain the same" (Henderson 1833). After he had examined his extensive set of microscope comparisons, Henderson was able to assert that "...the accuracy of the Astronomical Observations is not impaired by the anomalies of the Instrument, and that it is little (if at all) inferior in accuracy to the best Instruments of similar construction hitherto made" (Henderson 1834a). 
Table 1. Dates of Mural Circle observations of $\alpha$ Centauri

\begin{tabular}{lll}
\hline$\alpha^{1}$ & Direct & 1832: $23 / 5,11 / 6,19 / 8,23 / 9,11 / 10,9 / 11,15 / 12$ \\
& & $1833: 12 / 1,8 / 4,10 / 4,13 / 4,21 / 4,28 / 4,30 / 4,2 / 5,9 / 5,16 / 5$ \\
& Reflected & $1832: 27 / 7,5 / 9,14 / 9,21 / 9,25 / 9,3 / 10,7 / 10,31 / 10,8 / 11$ \\
& & $1833: 28 / 1$ \\
$\alpha^{2}$ & Direct & $1832: 22 / 5,28 / 5,6 / 7,16 / 7,12 / 9,24 / 9,30 / 10,12 / 11,13 / 12$, \\
& & $1833: 9 / 1,14 / 1,9 / 4,12 / 4,20 / 4,25 / 4,29 / 4,1 / 5,4 / 5,11 / 5,20 / 5$ \\
& Reflected & $1832: 6 / 8,20 / 8,11 / 9,22 / 9,14 / 10,16 / 10,29 / 10,7 / 11$ \\
& & $1833: 8 / 1$ \\
\hline
\end{tabular}

Observatories, an advantage... I never have had an opportunity to enjoy" (Warner 1982). This was granted on 13 May and he left within a few days (the precise date of sailing is not known).

By the time that Johnson left St Helena he had accumulated sufficient observations to form a catalogue. Johnson intended to return and extend his work, but in August 1833, while he was away, the East India Company's garrison on St Helena was dispersed when an Act of Parliament transferred the island to control by the British Government. His reductions were evidently in an advanced state, for shortly after his arrival in England he presented the Royal Astronomical Society with a catalogue of declinations of 598 stars, the manuscript of which is still in the Archives of the RAS and is dated as received 14 June 1833. The final catalogue, expanded to include both right ascensions and declinations of 606 stars, was privately printed in 1835 (Johnson 1835). The RAS, using Henderson as a referee, judged the catalogue of such high quality that they awarded Johnson the Society's Gold Medal in January 1835. The draft introduction to the catalogue still exists, with comments in Henderson's hand (Oxford).

From the Introduction to the catalogue we learn that it was while making comparisons between his own catalogue and those of others, especially Lacaille (from observations made in 1751 and published by Baily in 1831 (Baily 1833)), that Johnson discovered the large proper motion of $\alpha$ Cen. Although there were other differences between the two catalogues, that for $\alpha$ Cen was too large to ascribe to anything other than proper motion. Henderson left the Cape on 28 May 1833, and had received Johnson's letter about the proper motion not long before departing, so Johnson must have started work on his reductions (at least the declinations) and sent his letter to Henderson from St Helena some time before he left his own observatory. The letter, which would be of some historic interest, has not been found. The immediate delivery on arrival in England to the RAS of Johnson's preliminary catalogue again suggests that he had completed at least the declination catalogue before he left St Helena, the work for which revealed the large proper motion of $\alpha$ Cen.

\section{Henderson's measurements of $\alpha$ Centauri}

Henderson's parallax paper (Henderson 1840) contained just 17 measurements of $\alpha^{1}$ Cen and 20 of $\alpha^{2}$ Cen made by 'direct' observation, and 10 of $\alpha^{1}$ Cen and 9 of $\alpha^{2}$ Cen made by 'reflected' observation. The latter used a trough of mercury in which to see the reflected image of the star - a relatively new process at the time that enabled accurate declinations to be determined, independent of knowledge of latitude, from averages of the direct and reflected altitudes. The observations were made on the dates shown in Table 1.

The declination measurements were made personally by Henderson with the mural circle of the Cape Observatory. Over the same period of time, April 1832 to May 1833, measurements were obtained with the Observatory's transit instrument, by the assistant, 
Lieutenant William Meadows, which provided 24 observations of $\alpha^{1}$ Cen and 25 of $\alpha^{2}$ Cen. Henderson and Meadows observed $\alpha$ Cen simultaneously on only two nights, presumably because they worked separately through the list of stars to be observed.

The total number of independent observations was therefore 105, spaced unevenly over just one Earth orbital period, with (as seen in Table 1) a heavy concentration in April and May 1833 until 8 days before Henderson left the Cape - which suggests that he received Johnson's letter about a month before he embarked. The only two ships arriving from St Helena during that period were the Meta, which left St Helena on 26 February and arrived at the Cape on 21 March, and the Lord Hobart, which left on 20 March and arrived on 14 April. It presumably was the latter that brought Johnson's letter. Despite the increased frequency of transit observations made by Johnson and Meadows in April and May 1833, on only the first (8 April) and penultimate (16 May) observing nights did they make simultaneous observations. Although the earliest observations in April might appear to have anticipated the arrival of Johnson's letter, there had been no measurements made in February or March, and Henderson and Meadows were merely starting their observations again at a time similar to the first observations of the previous year.

The result from this set of observations, which were poorly distributed, under-sampled and generated by a slightly suspect instrument, was a parallax $\pi=1$.' $16 \pm 0$ "' 11 , obtained from six independent groups of measurements (viz. each star observed with the transit instrument and by direct and by reflected observation with the mural circle) $\dagger$. The spread was from 0 ". 48 to 1 ". 96 , but the fact that all the measurements were positive certainly suggested that a parallax effect had been detected. Main (1842), in reviewing the state of parallax measurements in 1840, reanalyzed Henderson's measurements and found that for the deviations from the mean (at least for $\alpha^{1}$ Cen) "there is scarcely an exception to the proper change of sign, according to the change of sign of the coefficients of parallax", and therefore accepted the evidence for parallax "until some distinct reason, independent of parallax, shall have been assigned for the changes in the declinations. Such I do not consider impossible, having before my eyes the results which Dr Brinkley derived, in the cases of certain stars, with the Dublin circle)". (The central problem in parallax measurement with meridian circles is that one is looking for a modulation in position with a period of a year - and this may occur merely from the summer/winter variations in observing conditions.)

\section{The delay}

From a modern perspective the delay between Henderson's receipt of Johnson's letter about $\alpha$ Cen in 1833 and his working on the issue in 1839 seems perplexing. It is clear from the following comment in a letter to Maclear at the end of 1838 that it was Bessel's announcement (in a letter to John Herschel, dated at Königsberg 23 October, 1838: Bessel 1838) of his detection (with the use of a heliometer) of a parallax in 61 Cyg that finally moved Henderson into action: "The question of the parallax of the Stars is again making a stir, from Bessel having announced that he makes a parallax of $\frac{1}{3}^{d}$ of a second in 61 Cygni. I have sent off a Paper on the parallax of $\alpha$ Centauri to the Astronomical Society, and I enclose a copy" (Henderson 1838b).

In his $\alpha$ Cen paper, Henderson's explanation of the cause of the hiatus was that "I delayed communicating the result till it should be seen whether it was confirmed by the

$\dagger$ Henderson was among the first astronomers to use Gauss's method of least squares and to derive probable errors therefrom. 
observations of Right Ascension made by Lieutenant Meadows". This rather sounds as if he had to wait for the RA measurements to be sent to him, but in fact he took copies of them with him when he left the Cape in 1833 . What had actually happened was that he had set himself a program of work and publication of the Cape observations. This can be traced through successive letters to Maclear (RGO Archives), for example, 29 Sep 1834 - "I am devoting as much time as possible to the reduction of the Cape Observations, but the labour is immense, and my interruptions have been frequent. I am investigating several points which have been scarcely attended to in English Observations, for instance the magnitude of the numerical Coefficients which enter into the formulae of refraction. I expect to have the first great division of the work, the Declinations, ready about the new Year. The Right Ascensions will follow next"; two years later, on 20 September 1836 - "I am now engaged with the Memoir upon the Cape Declinations. When it is finished I shall prepare one shewing the observations of refractions of Stars near the Horizon, and their results. The calculations are ready. Next I intend to investigate the constant quantity of the Moon's parallax from my Cape observations compared with those of Greenwich and Cambridge.... Then I shall devote myself to the Right Ascensions of the Stars". In addition to these projects he worked on the solar and lunar parallaxes and many minor issues.

It is evident that, because of this plan of action, combined with the problems of getting the observatory in Edinburgh into operation, Henderson did not get to the extensive reductions required for the right ascensions, the results of which would be needed for use on $\alpha$ Cen, until the perceived more urgent matters were completed. He published a series of papers in the RAS Memoirs on these more pressing topics. Nowhere in his correspondence before the end of 1838 is there any awareness of urgency to seek parallax in $\alpha$ Cen.

Henderson, although having finally investigated his and Meadows's observations, and having committed himself to the public announcement in 1839, wrote to Sheepshanks that he had "not very great confidence in my parallax of $\alpha$ Centauri; but I thought it might be right to let it be known that my observations were better satisfied by the hypothesis of parallax†. I am anxious to learn in due time the result of additional observations. I wrote to Maclear two months ago with a copy of my Paper" (Henderson 1839). In the letter to Maclear, Henderson said that "I recommend to you to make as numerous a set of observations as you can for the space of a twelvemonth at least, to ascertain beyond doubt whether there is a sensible parallax... perhaps your most convenient mode of observation is the measurement of the double Altitudes of the two Stars, with the Mural Circle" (Henderson 1838b).

\section{Maclear's measurements of $\alpha$ Centauri}

Maclear was sufficiently impressed with Henderson's work to tell Sir John Herschel "Henderson sent me a copy of his paper on the parallax of $\alpha^{1} \& \alpha^{2}$ Centauri. The result appears palpable enough although the observations are not so numerous nor well placed as they might be. Therefore I have taken up the subject" (Maclear 1839). Maclear's observations were sent to Henderson for reduction and resulted in Henderson's second paper on the subject, read to the RAS on 8 April 1842 (Henderson 1842). This contained observations from 26 March 1839 to 12 August 1840, comprising 124 individual

$\dagger$ This statement, which is that of a true scientist rather than a mere measurer and cataloguer, suggests that Henderson had, as with so many other scientists of the time, been influenced by John Herschel's treatise published a few years earlier (Herschel 1830). 
measurements of $\alpha^{1}$ and $\alpha^{2}$ Cen with the original mural circle and 483 with the replacement mural circle, sent out from Greenwich. These provided 134 measurements of double altitudes of $\alpha^{1}$ Cen and 138 of $\alpha^{2}$ Cen, made at same transits, distributed around the year but with higher concentration near the months of April and October when the parallax factors in declination are maximal for $\alpha$ Cen.

This was a very substantial amount of observational work, especially because the double altitude method required extra effort. As Maclear mentioned to Herschel: "Considerable dexterity is required to take each star of a double star by direct vision \& reflexion at the same transit; the errors of observation are greater. A micrometer has to be read twice independent of the bisections at or near to the second wire - again, two bisections at the $4^{\text {th }}$..." (Maclear 1840). Henderson's deduced result from Maclear's generous effort was $\pi=00^{\prime \prime} 9128 \pm 00^{\prime \prime} 0640$. The modern value is 0.785 , which confirms that it certainly was within reach of the meridian instruments of the time.

\section{Conclusion}

Henderson evidently thought that his small number of observations of $\alpha$ Cen would not show the presence of parallax, and therefore left it to Maclear to carry out his 1834 recommendation to follow up on the clue of large proper motion. In 1838, with nothing forthcoming from Maclear, Henderson, inspired by Bessel's success, analysed his $\alpha$ Cen observations for the first time - which would not have taken much time because by then he had all the basic reductions of the Cape declinations and right ascensions under control. It probably came as a surprise to find such clear evidence for parallax, which gave him the confidence to publish immediately.

\section{References}

Baily, F. 1833 Mem R.A.S. 5, 93.

Bessel, F.W. 1838 MNRAS 4, 152.

Brinkley, J. 1815 Trans. Roy. Irish Acad. 12, 33.

Henderson, T. 1832 Letter, 25 January 1832, TH to T. Maclear, RGO Archives.

Henderson, T. 1833 Letter, 24 October 1833, TH to T. Maclear, RGO Archives.

Henderson, T. 1834a Letter, 31 January 1834, TH to T. Maclear, RGO Archives.

Henderson, T. 1834b Letter, 14 June 1834, TH to T. Maclear, RGO Archives.

Henderson, T. 1835 Mem. R.A.S. 8, 141.

Henderson, T. 1838a Mem. R.A.S. 10, 49.

Henderson, T. 1838b Letter, 26 December 1838, TH to T. Maclear, RGO Archives.

Henderson, T. 1839 Letter, 23 February 1839, TH to Richard Sheepshanks, RAS Archives.

Henderson, T. 1840 Mem. R.A.S. 11, 61.

Henderson, T. 1842 Mem. R.A.S. 12, 328.

Herschel, J.F.W.H. 1830 A Preliminary Discourse on the Study of Natural Philosophy, Longmans, London.

Johnson, M.J. 1835 A Catalogue of 606 Principal Fixed Stars in the Southern Hemisphere, Privately printed, London.

Maclear, T. 1839 Letter, 3 April 1839, TM to J. Herschel, Library of The Royal Society of London.

Maclear, T. 1840 Letter, 19 February 1840, TM to J. Herschel, Ibid.

Main, R. 1842 Mem. R.A.S. 12, 1.

Oxford Museum of the History of Science, Papers of the Radcliffe Observatory.

Pond, J. 1817 Phil. Trans. Roy. Soc. 107, 158.

Sheepshanks, R. \& Airy, G.B. 1833 Mem. R.A.S. 5, 325. 
Warner, B. 1979 Astronomers at the Royal Observatory, Cape of Good Hope, Balkema, Cape Town.

Warner, B. 1982 Vistas in Astr. 25, 383.

Warner, B. 1995 Royal Observatory, Cape of Good Hope 1820-1831, Kluwer, Dordrecht.

\section{Discussion}

WAYNE ORChISTON: Is there any evidence to show why, in fact, Maclear wasn't co-author on the 1832 paper, because there's not any documentation online about that?

Brian WARner: No. The two were very, very close friends. Henderson died in 1846 and Maclear was dreadfully hard hit by that. Maclear was doing it as a friendly gesture; certainly Maclear was way over his head with his observational work and stuff at the Cape Observatory. He had not himself the time to go through what was a very accurate set of reductions, so I think he generously gave to Henderson. And if you look at those times, there was not a great deal of co-authored papers at that time; it was usually a senior person who was using other people's data, so I don't think there was anything in it than that. Maclear was asked a favour; he did a favour. Henderson actually had a huge amount of work doing the reductions and he says in the title it was based on Maclear's observations. I don't think one should read too much into that.

CORYN BAILER-Jones: You alluded to the answer just now, but one perspective, of course, is why not look at the parallax anyway? Just do the data reduction; but of course it does take long, or it would then have taken long. Do you have any idea of how long that kind of analysis would have taken for that data set?

BRIAN WARNER: Henderson's declination catalogue contains 196 stars, including $\alpha$ Cen, and it looks to me as though there was nearly one whole year's hard labour; it took him five years to do it. It was all done with logarithm tables, it was a huge amount of manual labour, but for someone who was observing at night, trying to build an observatory in the daytime, it was a huge amount of manual labour. I think that's why it was so slow. The whole idea that there might be a detectable parallax in those first observations evidently didn't occur to him at all. I'm sure he was quite astonished to find what was done; but when you needed to do it, all the data reductions were there, all you had to go back and do was add the parallax factor, He would have removed aberration, he would have removed nutation, he would have removed everything except parallax and proper motion. He probably didn't remove proper motion for $\beta$ and $\alpha$ Cen. So that part probably took him a week - it was easy, once the notion was in his mind, but the concept wasn't there in 1833 - to look for effective parallax - and he would've been nervous, as I said. Everybody got it wrong up until that moment.

Nicole Capitaine: Are there other stars for which the parallax would have been detectable at that time?

Brian Warner: Bessell came up with 61 Cygni and at about the same time Struve did - what was it? $-\gamma$ Draconis. There were 3 measurements all announced at the same time. Struve's observations had been made in 1838-1839; and as I said, Henderson's were actually made in 1832-33. And they used different techniques of course. You see, Henderson's was an absolute measurement of position, of declination; what Struve and Bessell did were differential measurements, which is potentially much more accurate. He was using a micrometer in the eyepiece to measure the difference in position between, say, 61 Cygni and a nearby star in the same field. That's the right way to do it. You 
may remember Bradley tried to do that in the 1720s to measure parallax and discovered aberration. So there were three, suddenly. Henderson then published a paper showing that there was no detectable parallax in six or eight other bright stars, so he only got one positive result.

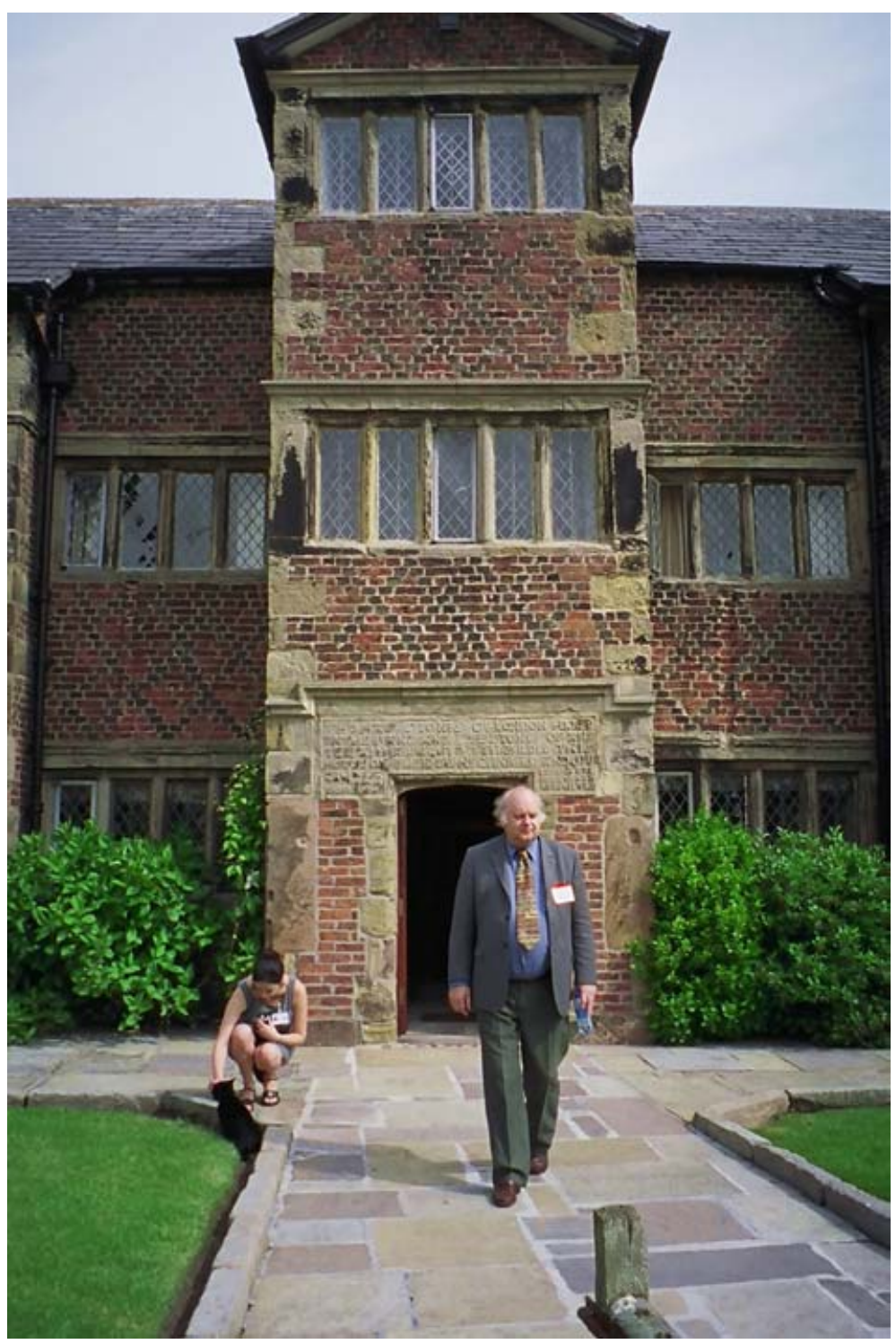

Brian Warner at Carr House 


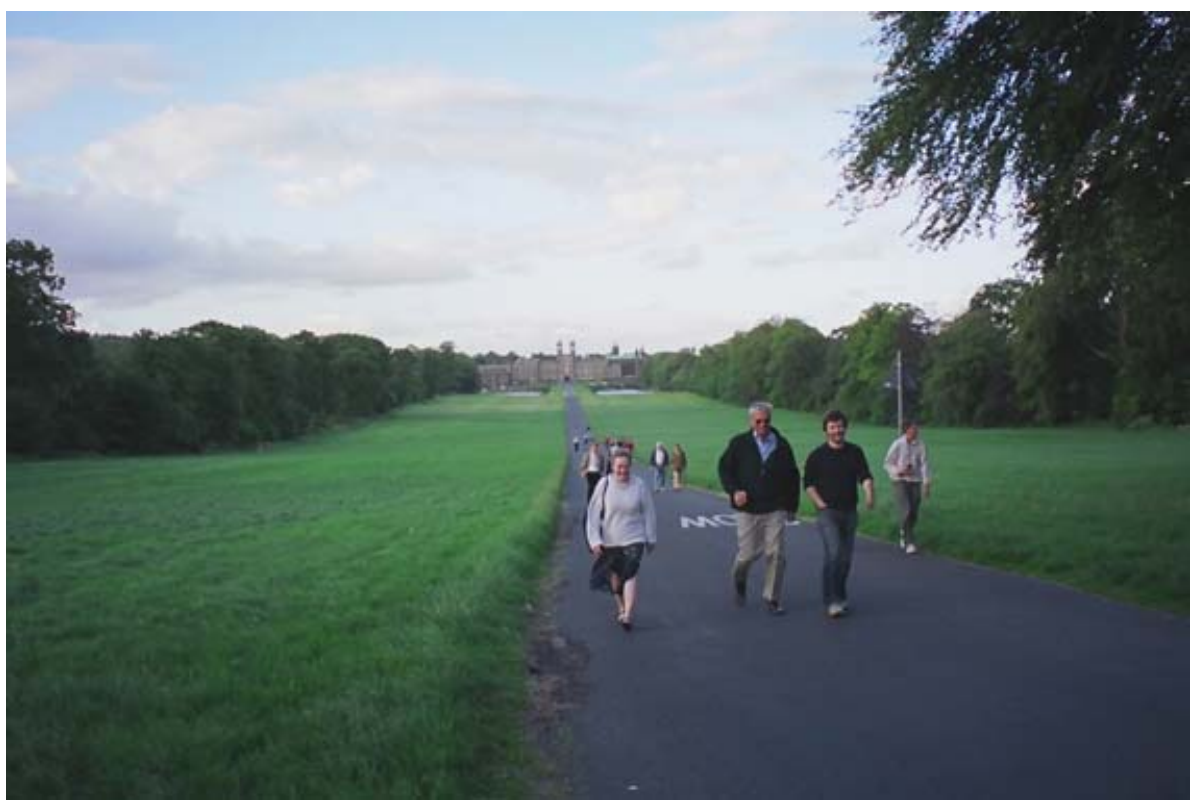

Anne Lemaitre, Myles Standish and Menios Tsiganis on a brisk walk from Stonyhurst College to the Shireburn Arms

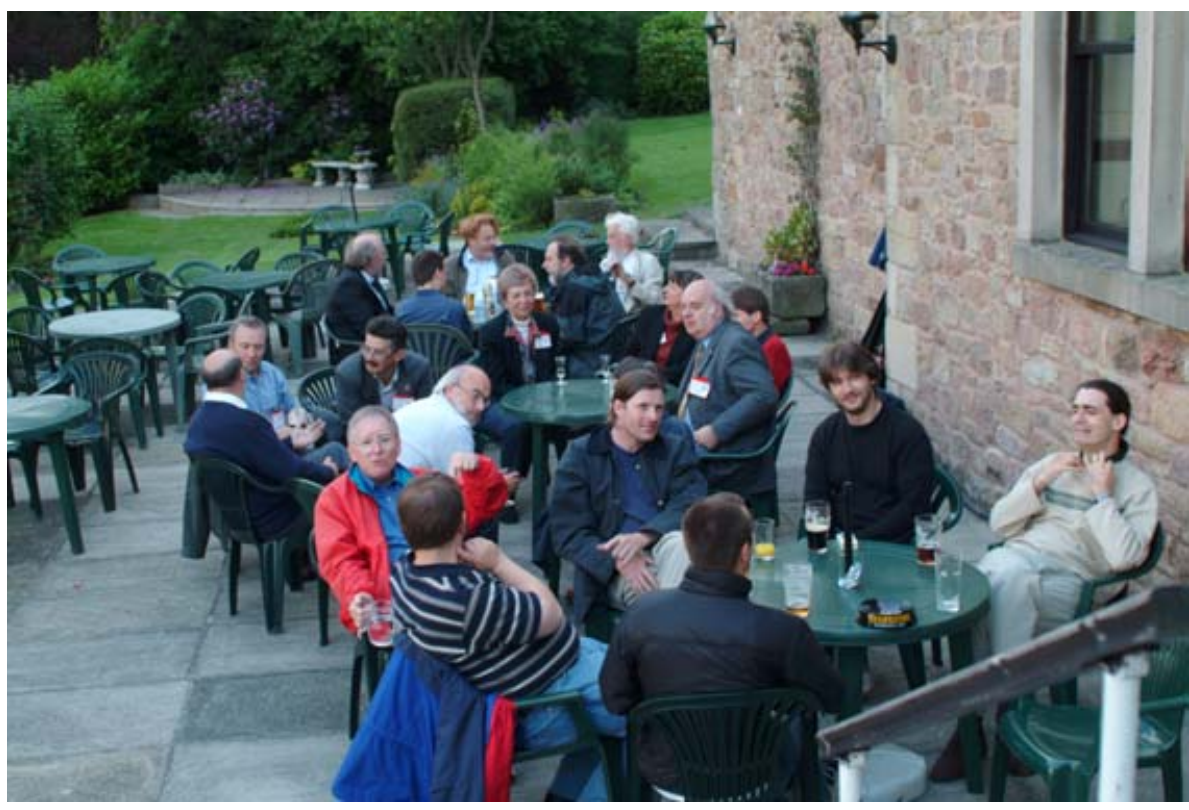

The Shireburn Arms was a favourite "watering hole" of J. R. R. Tolkien; it is locally believed that much of the Lord of the Rings was imagined in and around Hurst Green and Stonyhurst College, where Tolkien's sons taught. 